\title{
Locus of Causality Differences in the Writings of University Students According to Gender and Topics of Writing
}

\author{
Kyungjae Lee \\ Department of Audiology and Speech-Language Pathology, Catholic University of Daegu, Gyeongsan, Korea
}

Correspondence: Kyungjae Lee, $\mathrm{PhD}$ Department of Audiology and Speech-Language Pathology, Catholic University of Daegu, 13-13 Hayang-ro, Hayang-eup, Gyeongsan 712-702, Korea

Tel: $+82-53-850-2543$

Fax:+82-53-850-3383

E-mail: kjlee0119@cu.ac.kr

Received: January 5, 2013

Revised: February 15, 2013

Accepted: February 28, 2013

This work was supported by research grants from the Catholic University of Daegu in 2012

\begin{abstract}
Objectives: One important factor for facilitating and maintaining behavioral changes is the locus of causality (LOC). LOC indicates personal perception on whether causes of behaviors are within or outside the agent, which are Origin and Pawn, respectively. Previous studies determined the LOC through analyses of writing samples of general or communication-related topics. In Korea, most studies were conducted to determine speech-related LOC of male adults who stutter. Purposes of the current study are to determine whether the LOC and the length of writing samples of normal university students would differ according to gender and the topics of the writing samples. The current study intends to provide insights on the attitude of university students toward communication, and needed data for comparison with data those with communication disorders. Methods: Each of 22 university students wrote two writing samples, which were analyzed to determine speech-related and general LOC. Differences in LOC and the lengths of the writing samples according to gender and topics were examined. Results: There was a statistically significant difference in the length of writing samples according to gender and writing topics. However there was no statistically significant difference in LOC, even though the effect sizes for gender differences were greater than medium-sized. Conclusion: Results of the current study suggest that the speech-related LOC of normal university students are based on general characteristics. Furthermore, in order to clarify subtle gender differences, future studies should incorporate greater numbers of participants and more-controlled settings.
\end{abstract}

Keywords: locus of causality, origin, pawn, gender differences, communication-related characteristics
자기 자신의 행동의 원인과 이러한 행동을 통제하는 힘의 위치 에 대한 믿음은 변화를 촉진시키고 이를 유지하는데 매우 중요한 요소로 심리 및 행동치료 분야에서 연구가 시작되어, 말더듬, 청능 재활 등을 포함하는 언어청각치료 분야에서도 적용되었다(Ajzen, 2002; Craig, Franklin, \& Andrews, 1984; DeCharms, 1968; De Nil \& Kroll, 1995; Garstecki \& Erler, 1998; Lee, Manning, \& Herder, 2011; Rotter, 1966; Strickland, 1989). 언어치료 분야에서는 특히 말 더듬 치료에서 이에 대한 연구가 활발하였는데, 이는 말더듬성인 치료의 경우 말하기 습관을 변화시키고 유지하는 것이 매우 중요
하며, 이러한 치료 중 변화를 촉진하고 치료 종료 후에도 이를 유지 하는데 심리적인 변화가 중요하다는 견해가 있어왔기 때문이었다 (Craig et al., 1984; De Nil \& Kroll, 1995; Lee et al., 2010).

하지만 행동을 통제하는 힘의 위치인 통제소와 행동원인의 위치 와 관련된 인과소는 유사하지만 서로 다른 개념이다(Ajzen, 2002; Craig et al., 1984; DeCharms, 1968; Rotter, 1966; Westbrook \& Viney, 1980). 우선 통제소(locus of control of reinforcement, 혹은 locus of control)는 행동의 강화물이 어디에 위치하는지를 나타내 며, 크게 내재적 통제소와 외제적 통제소로 이루어진다(Rotter, 
1966). 행동의 강화물이 자기 자신 내부에 위치한다고 믿는 경우를 내재적 통제소(internal locus of control), 운명, 운과 같은 외부적인 요소에 위치한다고 믿는 경우를 외재적 통제소(external locus of control)라고 한다. 이러한 통제소는 행동주의 학습이론에 바탕을 두고 있으며, 인간이 어떻게 행동을 습득/학습하는지를 설명하는 데 사용되었다(Rotter, 1966). 행동주의적 학습이론에 따르면 행동 의 강화물이 외부에 위치한다고 믿는 경우, 즉 외재적 통제소의 경 우보다는 행동 강화물이 자기 자신에게 있다고 믿는 경우, 즉 내재 적 통제소가 학습에 더 효율적일 수 있다.

이러한 통제소를 측정하는 데에는 설문지 형태의 검사도구가 주 로 사용되었다. 예를 들어서 심리학분야에서 성인의 통제소를 측정 하는 데에는 내재적, 외재적 통제소를 기술하는 두 개의 보기에서 하나를 골라야 하는 총 23 문항으로 이루어진 설문지 형식의 검사 도구인 I-E Scale (Rotter, 1966)이 주로 사용되었으며, 언어치료분 야에서는 라이케르트 타입 형식의 17문항으로 이루어진 The Locus of Control of Behavior (LCB; Craig et al., 1984)가 주로 사용되 었다. 이와 같은 설문지 형식의 검사도구는 짧은 시간 안에 검사를 끝낼 수 있으며 자료분석 시 검사자간 신뢰도가 높다는 장점이 있 다. 하지만 제한된 수의 문항은 개인의 폭 넓은 다양한 경험을 민감 하게 나타내지 못할 수 있다는 단점이 있다.

통제소에 영향을 줄 수 있는 다양한 요소에 대한 연구가 있어왔 으나 몇몇 개인적인 요소에 대한 결과는 일관적이지 않았다. 이전 연구에 따르면 문화적 배경, 인종, 사회경제적 위치 등 사회문화적 요소와(Gergen, 1985; Gurin, Gurin, \& Morrison, 1978; Lefcourt, 1992), 신체 및 심리장애와 같은 장애 요소(Benassi, Sweeney, \& Dufour, 1988; Craig et al., 1984; Marks, 1998)가 통제소와 관련이 있는 것으로 보고되었다. 하지만 성과 연령에 따른 통제소의 차이 는 일관적이지 않았다. 예를 들어서 성 차이는 대학생의 경우 가장 크게 나타나며, 남성이 여성보다 더 내재적인 통제소를 보인다고 보 고되었다(Maccoby \& Jacklin, 1974). 반면 Craig 등(1984)에 따르면 LCB 점수는 성과 연령에 따른 차이를 보이지 않았다. 이와 관련하 여 일반화된 통제소는 시간/연령에 따라 크게 변화하지는 않지만 특정 상황/영역에 대한 통제소는 변화하리라는 제안도 있었다(Schulz, Heckhausen, \& Locher, 1991).

인과소는 통제소와는 다른 이론적 배경을 지녔으며, 개인의 특성 과 변화를 좀 더 민감하게 나타낼 수 있을 것으로 제시되었다. 통제 소의 이론적인 배경인 행동주의적 학습이론과는 달리 DeCharms (1968)는 인간이란 원래 주위의 환경을 변화시키고자 하는 성향을 타고났다고 주장한다. 비록 이러한 성향을 인간이 타고나기는 하지 만 상황에 따라 어떠한 행동을 하는 데 스스로 원해서 하는 경우도
있고, 원하지는 않지만 외부적인 요소, 혹은 운 등의 상황으로 인해 어쩔 수 없이 하게 되는 경우도 있게 된다. 행동 강화물의 위치와 관 련된 통제소와는 달리 인과소(locus of causality)란 행동의 원인이 어디에 위치하는지에 대한 행위자의 인식을 의미한다. 인과소 역시 둘로 이루어지는데, 행동의 원인이 행위자 내부에 있다고 인식하는 상황을 오리진(Origin), 행위자 외부에 있다고 인식하는 상황을 폰 (Pawn)이라고 DeCharms는 명명하였다. 특히 오리진과 폰으로 이 루어진 인과소는 이원적인 개념이기에 대상자의 특성을 좀 더 민감 하게 나타낼 수 있다. 이전 연구들은 오리진과 폰은 서로 음의 상관 관계를 갖는, 일차원적인 개념의 양 극단이 아니라는 점을 보고하 면서, 인과소와 통제소는 서로 다른 개념이며, 인과소가 좀 더 변화 를 민감하게 나타낼 수 있었다고 보고하였다(Lee et al., 2011; Westbrook \& Viney, 1980). 환언하자면 높은 오리진 성향을 보이는 사 람이 꼭 낮은 폰 성향을, 혹은 이와는 반대로 낮은 오리진 성향을 보이는 사람이 꼭 높은 폰 성향을 보일 필요는 없다는 것이다. 또한 집중치료를 받은 말더듬성인은 총 네 가지의 오리진과 폰 변화양상 을 보였다(Lee et al., 2011).

인과소의 이원적인 특성 뿐 아니라 내용분석 역시 대상자의 다 양한 특성을 민감하고도 충실히 측정하는데 도움을 주는 것으로 지적되었다(DiLollo, 2001; Finn, 1996; Gottschalk \& Gleser, 1969; Lee et al., 2011; Westbrook \& Viney, 1980). 초기 인과소 측정에는 투사적인(projective) 방법이 사용되었으나, 이러한 방법은 학습하 기가 어려우며 신뢰도가 낮을 수 있다는 단점이 있다(Plimpton, 1970). 이와는 달리 내용분석은 객관적인 절차를 이용하여 개인이 사용하는 언어를 분석하여 심리적인 특성을 측정하기에, 개인의 심 리적인 특성을 신뢰롭고 타당하게 나타낼 수 있다는 장점이 있다 (Gottschalk \& Gleser, 1969). 이러한 내용분석절차를 이용한 인과 소 측정도구가 바로 오리진-폰 분석도구(The Origin and Pawn Scales; Westbrook \& Viney, 1980)이다. Westbrook와 Viney (1980) 는 이를 이용하여 사지마비를 보이는 사람, 성공적인 대학생, 임신 한 주부 등으로 이루어진 다양한 집단을 대상으로 인과소를 분석 하였는데, 그 결과, 각 집단에 따라 인과소는 차이가 있었으며, 적극 적인 대응방식 등과 유의한 상관관계를 보였다. 이러한 결과는 내 용분석을 이용한 인과소 분석이 민감하고도 타당한 분석방법이라 는 것을 나타낸다. 비록 내용분석이 위와 같은 장점이 있지만 평가 자 간 신뢰도가 낮을 수 있다는 단점이 있다. 하지만 Viney (1983)는 평가자 훈련을 통하여 평가자 간 신뢰도는 적절한 수준으로 달성될 수 있다고 보고하였다.

비록 내용분석도구를 이용한 인과소 분석이 위와 같은 장점이 있지만 아직 국내에서 이를 이용한 연구는 많지 않으며, 말더듬성 
인의 쓰기자료를 대상으로 오리진-폰 검사도구의 적용을 소개한 정도였다(Lee \& Shin, 2010). Lee와 Shin (2010)은 말더듬성인의 의 사소통과 관련된 인과소를 분석하기 위하여 “말더듬과 나”라는 주제의 쓰기자료를 분석하였으며, 분석 결과, 한국 말더듬성인은 외국 말더듬성인과 마찬가지로 의사소통과 관련된 인과소의 경우 높은 폰 점수와 낮은 오리진 점수의 형태를 나타내었다. 하지만 성 에 따라서 인과소와 같은 심리적인 성향은 달리 나타날 수 있기에 참가자가 모두 말더듬성인 남성으로 이루어진 위 연구결과는 제한 적일 수 있다.

인과소를 포함하는 심리적인 성향 혹은 특성의 성 차이에 대한 연구는 장애의 진단/평가 과정뿐 아니라 치료과정을 좀 더 개별화 하는데 도움을 줄 수 있을 것으로 기대된다. 의사소통과 관련된 남 녀 성 차이에 대한 연구는 비록 일관적인 결과를 보고하고 있지 않 으나 메타연구에 따르면 여성은 남성에 비해 구어능력이 더 높으며 (Hyde \& Linn, 1988), 여성은 남성에 비해 설득적인 메시지에 더 많 이 영향을 받고(Eagly \& Carli, 1981), 남성이 여성에 비해 더 자기주 장성이 높다(Eagly \& Steffen, 1986). 하지만 의사소통장애, 특히 말 더듬을 보이는 집단의 경우에는 의사소통태도의 성 차이는 비일관 적으로 나타났다. 예를 들어 말더듬아동의 경우 여자아동이 남자 아동보다 더 높은 수준으로 의사소통에 대한 부담감을 나타내었으 나, 일반아동의 경우에는 의사소통태도에서 성 차이가 나타나지 않았다(De Nil \& Brutten, 1991). 이와는 달리 말더듬성인 여성은 말더듬성인 남성 보다 의사소통태도가 더 긍정적이었다는 결과도 있다(Silverman, 1980). 더불어 전술한 통제소 연구(Maccoby \& Jacklin, 1974)와 마찬가지로 인과소 연구에서도 성에 따른 차이는 일관적으로 나타나지는 않았으나 대학생 연령대에서 그 차이가 가 장 두드러질 것으로 기대된다. 예를 들어 Westbrook와 Viney (1980) 는 길거리에서 마주친 청소년, 성공적인 대학교 2학년생, 고등학교 를 마치고 이제 막 대학에 등록한 학생, 그리고 환자의 가족 등 총 네 집단을 대상으로 오리진과 폰 점수의 성 차이를 분석하였는데, 오직 성공적인 대학교 2 학년생 만이 오리진 점수에서 성 차이를 나 타내었다. 이들의 경우 남성이 여성 보다 더 높은 오리진 점수를 보 였다. 성 차이 이외에도 장애 유무에 따른 인과소의 차이가 제한적 으로 연구되었으나 기타 다른 개인적, 사회문화적 요소가 인과소 에 어떠한 영향을 주는지에 대한 실증적인 연구는 아직 부족한 편 이다(Viney, 1983). 본 연구와 같은 참여자의 특성에 영향을 줄 수 있는 요인에 대한 연구를 통하여 임상가는 장애의 진단과 치료 시 고려할 수 있는 참여자의 개별성향에 대하여 좀 더 깊은 이해를 할 수 있을 것이다.

또한 개인의 성향은 상황에 따라 다른 반응으로 나타날 수 있으
므로, 특정 상황, 특히 의사소통과 관련된 성향은 일반적인 성향과 구별하여 연구할 필요가 있을 것이며, 이를 통하여 궁극적으로는 의사소통장애를 지닌 사람들의 특성을 좀 더 잘 이해할 수 있을 것 이다. 예를 들어 인과소는 특정 상황에서 나타나는 행동 원인에 대 한 믿음이므로, 상황에 따라 달리 나타날 수 있다(DeCharms, 1968; Westbrook \& Viney, 1980). 하지만 일반인을 대상으로 하는 기존 해외 인과소 연구는 중립적인 주제를 이용하여 실험 참여자의 발 화샘플을 획득하고 이를 분석하여 일반적인 성향으로의 인과소를 측정하였을 뿐(Westbrook \& Viney, 1980), 일반인이 의사소통에 대하여 어떠한 인과소를 갖고 있는지에 대한 연구는 부족한 편이 다. 최근의 인과소 연구가 말더듬성인의 의사소통과 관련된 연구가 주를 이루고 있으므로(Lee \& Shin, 2010; Lee et al., 2011), 일반인이 의사소통에 대해서 어떠한 인과소를 가지고 있는지, 그리고 이러한 의사소통 관련 인과소가 일반적인 성향으로의 인과소와 차이가 나타나는지 살펴보는 것이 필요하며, 추후 의사소통장애 집단과의 비교도 가능할 것으로 기대된다.

본 연구의 주제는 의사소통에 문제가 없는 일반인이 중립적인 주 제와 의사소통 관련 주제로 작성한 글쓰기를 내용분석하여 산출 된 인과소가 주제에 따라, 그리고 성별에 따라 차이를 보이는지이 다. 특히 인과소는 참여자가 속하는 인생단계에 따라 달리 나타날 수 있기에, 본 연구는 인과소와 유사한 개념인 통제소가 성에 따른 차이를 가장 크게 나타내는 것으로 보고된 대학생 연령대를 참여자 로 하였다. 더불어 본 연구는 인과소를 측정하는데 사용되는 쓰기 자료의 길이가 성별과 주제에 따라 차이가 나타나는지 살펴보는 것 을 통하여 성별에 따른 의사소통양식의 차이 또한 살펴볼 것이다.

본 연구는 말더듬성인을 대상으로 사용된 적이 있었던 내용분 석도구인 오리진-폰 분석도구를 한국 일반 대학생을 대상으로 적 용하는 첫 연구가 될 것이다. 또한 본 연구는 의사소통과 일반적인 성향으로의 인과소를 비교함으로써 추후 의사소통에 문제가 있는 사람들의 의사소통과 삶의 질과 관련된 연구에 기초자료를 제공할 수 있을 것으로 기대된다. 특히 최근에는 장애를 삶의 질의 측면에 서 살펴보는 경향이 있으므로 본 연구는 추후 장애의 다면적인 측 면을 연구하는데 특히 도움이 될 것으로 기대된다(Yaruss \& Quesal, 2004).

\section{연구 방법}

\section{참가자}

본 연구에서는 대구·경북지역의 남녀대학생 각 11 명, 총 22 명의 글쓰기자료를 분석하였다. 참가자의 평균나이는 21 세(남성 범위: 
19-24세, 여성 범위: 19-22세)였으며, 남녀 사이에 유의한 차이는 없 었다 $(t(20)=.273, p=.788)$. 참가자들은 말·언어문제 및 기타 다른 문제가 없다고 보고하였으며, 연구자와의 상호작용 시 큰 문제가 관찰되지 않았다.

\section{도구 및 절차}

인과소 분석을 위한 두 가지 글쓰기 주제

참여자들은 두 가지 주제에 대하여 글쓰기를 하였으며, 이러한 글쓰기 자료를 내용분석하여 의사소통과 관련된 인과소와 일반적 인 성향으로의 인과소를 측정하였다. 첫 번째 글쓰기 주제는 "최근 의사소통 경험”이었다. 전술하였듯이 인과소는 특정상황에서의 행동원인에 대한 개인의 믿음이다. 최근 의사소통 경험에 대한 글 쓰기 자료는 참가자의 의사소통 관련 행동 및 인지, 감정적 반응에 대한 기술을 포함할 것이며, 이에 대한 분석은 참가자의 의사소통 관련 인과소를 나타낸다. 예를 들어 Lee 등(2011)은 본 연구에서 사 용한 것과 같은 주제의 글쓰기 자료를 분석한 결과가 말더듬성인의 의사소통 관련 인과소를 신뢰롭고 타당하게 나타내었다고 보고하 였다.

두 번째 주제는 “자기 인생에서 가장 흥미로웠던 일”이었으며, 이 러한 주제는 일반인을 대상으로 한 이전의 인과소 연구에서 사용 되었던 주제이다. 이전 연구에서는 이와 같은 일반적인 주제를 이용 하여 산출된 자료를 분석하여 일반적인 성향으로의 인과소를 분 석하였다(DeCharms, 1968; Westbrook \& Viney, 1980).

\section{실험절차}

전술하였듯이 참여자들은 대구·경북지역의 남녀대학생이었으 며 눈덩이 표집방법(snowball method)를 이용하여 참여자를 선정 하였다. 실험은 교수연구실, 학회실 등과 같은 조용한 장소에서 1-2 명의 참여자를 대상으로 실시되었다. 참여자들은 우선 실험참여동 의서를 읽고 서명하였다. 기본인적사항 작성 후 두 가지 주제의 글 쓰기를 무순으로 하였다. 참여자들은 각각의 주제로 글쓰기를 시 작하기 전에 각 주제에 대해서 생각할 수 있는 시간을 가졌다. 각각 의 주제에 대한 글쓰기 시간은 10 분이었으며, 이 동안 실험자와 실 험참여자와의 상호작용은 최소한으로 하였다. 글쓰기 방식과 기술 경험 수 등과 같은 세부 사항에 대해서는 이외의 다른 제약이 없었 기에 참여자는 자기 자신에게 가장 의미가 있었던 경험에 대해서 작성할 수 있었다. 이는 글쓰기 주제와 방식에 대해서 실험참여자의 자유를 최대한 보장하기 위함이며, 이러한 내용의 내용분석은 참 여자의 특성을 민감하고 타당하게 나타낼 수 있기 때문이다(Gottschalk \& Gleser, 1969; Westbrook \& Viney, 1980).

\section{자료 분석}

인과소 분석자료 준비

워드프로그램을 이용하여 글쓰기 자료분석 준비를 하였으며, 우선 글쓰기 자료의 길이를 정하였다. 글 자료의 길이는 추후 오리 진과 폰 점수를 산출하는데 길이보정계수로도 사용되며, 성과 주 제에 따라 자료의 길이가 달라지는지 또한 분석될 것이다. 영어를 이용한 이전 연구에서는 단어의 수를 이용하여 쓰기 혹은 발화자 료의 길이를 측정하였다(Lee et al., 2011; Westbrook \& Viney, 1980). 한국어를 이용한 이전 연구에서도 역시 단어의 수를 이용하여 쓰 기자료의 길이를 측정하였으나(Lee \& Shin, 2010) 본 연구에서는 연구분석의 편리성과 신뢰성의 증진을 위하여 어절 수로 글 자료의 길이를 측정하였다.

본 연구에서는 이전의 외국연구(Westbrook \& Viney, 1980)와 한국어 연구(Lee \& Shin, 2010)과 마찬가지로 절(clause)을 분석의 기본대상으로 하였다. 하나의 완전한 생각을 나타내는 절을 분석 의 기본대상으로 하였으며 이렇게 구분된 절을 “"으로 표시하였다. 이전 연구와 마찬가지로 안긴 문장은 “/””로 표현하였으며, 안긴 문 장을 포함하는 안은 문장을 독립된 두 개의 절로 분석하지 않았다.

\section{인과소 분석 방법}

인과소의 하위구분

인과소는 오리진과 폰으로 이루어지며, 본 연구는 이전 연구(Lee \& Shin, 2010; Lee et al., 2011; Westbrook \& Viney, 1980)의 오리진 과 폰 하위구분을 사용하였다. Lee와 Shin (2010)에 따르면 오리진 성향을 직접적으로 나타낼 수 있는 표현은 총 다섯 가지로 참가자 자신의 의도(“나는 말더듬을 꼭 고치겠다”), 노력(“나는 말속도를 조절하려고 하였다”), 능력(“나는 말속도를 조절할 수 있었다”) 등 을 표현하거나, 참가자 자신이 타인 또는 외부 요인의 영향을 넘어 섰다는 표현(“외부의 시선 따위는 잊을 것이다”), 스스로를 자기 행 동의 원인 혹은 오리진(“모든 결정은 나 스스로 하였다”)이라고 표 현하는 경우였다.

폰 성향을 직접적으로 나타낼수 있는 표현 또한 Lee와 Shin (2010) 에 따르면 다섯 가지로, 참가자 자신이 의도하지 않은 결과라고 표 현한 경우(“말더듬은 친구 때문이었다”), 참가자 자신의 노력(“다 행히도 유창하였다”) 혹은 능력(“나는 표를 살 수 없었다”)이 결여 되었다는 표현, 혹은 타인 혹은 외부의 영향을 직접적으로 표현 (“말더듬은 나를 의기소침하게 만들었다")하거나 스스로 폰 성향 을 나타낸 경우(“나는 어떻게 될지 모르겠다”) 등이었다. 


\section{오리진과 폰의 분석방법}

본 연구는 이전 연구의 오리진과 폰 분석지침을 활용하여 분석 을 실시하였다(Lee et al., 2011; Lee \& Shin, 2010; Westbrook \& Viney, 1980). 본 연구에서 사용한 주요 분석지침으로는 우선 참여 자의 오리진 혹은 폰 성향이 직접적으로 글쓰기 내용에 나타난 경 우에만 오리진과 폰 분석대상으로 하였다. 이전 연구와 마찬가지로 분석이 모호한 경우나 추측이 필요한 경우, 하나의 절에 오리진과 폰이 동시에 나타난 경우 등은 분석에서 제외하였다. 또한 하나의 절을 오리진 혹은 폰으로 분석하는 경우, 하위구분을 명시하지 않 았다. 이는 각각의 하위구분의 경계가 모호하여 신뢰도가 낮아질 우려가 있기 때문이었다.

\section{오리진과 폰 점수 산출방법}

각각의 글쓰기 자료에서 분석된 오리진과 폰 절의 수를 바탕으 로 Westbrook과 Viney (1980)는 다음과 같은 변환과정을 이용하 여 오리진과 폰 점수를 산출하였으며, 본 연구에서도 이를 이용하 였다. 우선 길이가 서로 다른 자료에서 관찰된 오리진과 폰 절의 수 를 보정하기 위하여 길이보정계수를 산출하였다. 즉 긴 자료에서 관찰된 오리진과 폰 절의 수는 짧은 자료에서 관찰된 오리진과 폰 절의 수보다 더 많을 수 있다는 점을 보완하였다. 또한 자료에서 오 리진이나 폰 절이 하나도 없는 경우 자료의 왜도(skewness)가, 그리 고 이러한 점수의 분포가 정상분포를 따르지 않을 수 있기에, 원래 절의 수에서 0.5 를 더하고 점수의 제곱근을 구함으로써 자료를 이 후 통계분석 사용에 적절하도록 변환하였다. 최종 변환과정은 다 음과같다.

길이보정계수 $=(1 /$ 자료의 어절 수 $) \times 100$

오리진 점수 $=\sqrt{(\text { 오리진 절수 }+0.5) \times \text { 길이보정계수 }}$

폰 점수 $=\sqrt{(\text { 폰 절수 }+0.5) \times \text { 길이보정계수 }}$

이러한 과정을 이용하여 의사소통 관련 글쓰기로부터 의사소통 관련 오리진과 폰 점수를, 가장 흥미로웠던 일이라는 일반적인 주 제 글쓰기로부터 일반적인 성향으로의 오리진과 폰 점수를 산출하 였다.

더불어 다른 연구와의 연구 방법상의 차이를 보완하며, 한 개인 의 오리진과 폰 성향의 직접적인 비교를 위하여 오리진과 폰 성향비 율을 구하였다. 이는 (오리진 점수/폰 점수) $\times 100$ 로 산출하였으며, 100 보다 큰 점수는 한 개인이 폰 성향보다는 오리진 성향을, 100 보 다 적은 점수는 폰 성향을 보다 크게 보이는 것으로 판단될 수 있다.

\section{신뢰도 및 통계분석}

본 연구의 연구자와 언어병리학 박사학위를 소지한 독립된 분석
가의 오리진-폰 분석결과를 비교하여 분석자간 신뢰도를 측정하였 다. 독립된 분석가는 본 연구의 연구자로부터 내용분석에 대한 연 습을 포함한 교육을 받은 후 신뢰도 측정에 임하였다. 총 참여자 22 명의 $20 \%$ 이상인 다섯 명의 글쓰기 자료를 임의로 선택하여 분석 자간 신뢰도를 Cohen's kappa를 이용하여 측정한 결과, 오리진 점 수는 .711, 폰 점수는 .797이라는 높은 수준의 신뢰도를 보였다. 신 뢰도 측정에서 불일치가 나타난 경우, 연구자와 독립된 분석가는 추후 이에 대한 논의를 하여 불일치를 해소하고자 하였다.

본 연구는 반복측정분산분석을 이용하여 오리진 점수, 폰 점수, 오리진-폰 점수 비율, 그리고 글쓰기 자료 길이가 성과 글쓰기 주제 에 따라, 그리고 이 둘의 상호작용에 따라 통계적으로 유의한 차이 를 보이는지 살펴보았다. 또한 이러한 차이의 크기를 Cohen's d를 이용하여 측정하였다. 더불어 오리진-폰 점수 비율이 균형된 상태 인 100 과 유의하게 다른지 일표본 $t$ 검정을 통하여 살펴보았다.

\section{연구 결과}

\section{성과 주제에 따른 글쓰기 자료 길이의 차이}

반복측정분산분석 결과, 일반적인 주제의 글쓰기가 의사소통 관련 글쓰기 보다 유의하게 긴 것으로 나타났다 $\left(F_{(1,20)}=19.421\right.$, $p<.001)$. 또한 여성대학생이 남성대학생 보다 더 유의하게 길게 작 성한 것으로 나타났으나 $\left(F_{(1,20)}=4.939, p=.038\right)$, 주제와 성 사이의 상호작용은 통계적으로 유의하지 않았다 $\left(F_{(1,20)}=.959, p=.339\right)$. Cohen's d로 측정한 일반적인 주제의 글과 의사소통 주제 글의 성 에 따른 길이차이의 효과크기는 각각 0.79 와 1.01 로 나타났다. 글쓰 기 자료, 절의 수, 오리진과 폰 절 수와 변환점수를 포함하는 연구결 과는 Table 1 에 제시되었다.

\section{성과 주제에 따른 인과소의 차이}

일반적인 주제와 의사소통 관련 글의 오리진 점수를 반복측정분 산분석을 이용하여 분석한 결과, 주제에 따른 오리진 점수의 차이 는 통계적으로 유의하지 않았다 $\left(F_{(1,20)}=.119, p=.733\right)$. 성에 따른 오 리진 점수 차이 역시 통계적으로는 유의하게 나타나지 않았으나 $\left(F_{(1,20)}=1.950, p=.178\right)$, Cohen's d로 측정한 일반적인 주제와 의사 소통 관련 글에서의 성에 따른 차이의 효과크기는 각각 0.68 과 0.30 으로 나타났다. 성과 주제 간의 상호작용 $\left(F_{(1,20)}=.228, p=.638\right)$ 역 시 통계적으로 유의하지 않았다.

폰 점수 역시 반복측정분산분석을 이용하여 분석한 결과, 일반 적인 주제와 의사소통 관련 주제 글 사이에서 통계적으로 유의한 차이가 나타나지 않았다 $\left(F_{(1,20)}=1.233, p=.280\right)$. 또한 성에 따른 차 
Table 1. Length and number of clauses of writing samples, number of Origin and Pawn clauses, Origin and Pawn scores and ratios of male and female university students' general and communicative topic writing samples

\begin{tabular}{lcc}
\hline & Male, mean (SD) & Female, mean (SD) \\
\hline Length of general topic writing & $102.82(48.28)$ & $133.73(27.62)$ \\
Clauses of general topic writing (no.) & $25.91(17.27)$ & $28.82(7.82)$ \\
Length of communicative topic writing & $73.82(42.84)$ & $115.27(39.24)$ \\
Clauses of communicative topic writing (no.) & $18.64(10.75)$ & $24.09(8.18)$ \\
Origin clauses for general topic (no.) & $2.27(2.15)$ & $1.55(1.21)$ \\
Origin scores for general topic & $1.55(0.66)$ & $1.19(0.36)$ \\
Pawn clauses for general topic (no.) & $2.91(2.98)$ & $3.55(2.74)$ \\
Pawn scores for general topic & $1.71(0.91)$ & $1.63(0.6)$ \\
Origin clauses for communicative topic (no.) & $1.64(2.38)$ & $1.55(1.29)$ \\
Origin scores for communicative topic & $1.53(0.78)$ & $1.33(0.54)$ \\
Pawn clauses for communicative topic (no.) & $1.91(2.07)$ & $1.36(1.12)$ \\
Pawn scores for communicative topic & $1.79(0.68)$ & $1.24(0.41)$ \\
Origin-Pawn scores ratio for general topic & $121.61(90.80)$ & $91.13(60.06)$ \\
Origin-Pawn scores ratio for communicative topic & $102.93(69.27)$ & $122.06(82.71)$ \\
\hline
\end{tabular}

이 역시 통계적으로 유의하게 나타나지 않았으나 $\left(F_{(1,20)}=1.581\right.$, $p=.223)$, Cohen's d로 측정한 일반적인 주제와 의사소통 주제 글 에서의 성에 따른 폰 점수 차이의 효과크기는 각각 $0.1,0.98$ 로 나타 났다. 폰 점수에서의 성과 주제 사이의 상호작용 $\left(F_{(1,20)}=2.777, p=\right.$ .111) 역시 통계적으로 유의하지 않았다.

오리진-폰 점수 비율 역시 주제 $\left(F_{(1,20)}=.071, p=.793\right)$ 와 성 $\left(F_{(1,20)}=\right.$ $.060, p=.809)$ 에 따른 차이가 반복측정분산분석 결과, 통계적으로 유의하지 않았으며, 이 둘의 상호작용 역시 유의하지 않았다 $\left(F_{(1,20)}=\right.$ $1.158, p=.295)$. Cohen's d로 측정한 일반적인 주제와 의사소통 주 제 글에서의 오리진-폰 비율의 성에 따른 차이의 효과크기는 각각 0.4 와 0.25 였다. 또한 네 가지 오리진-폰 비율, 즉 남성대학생의 의사 소통 관련 오리진-폰 비율 $(t(10)=.140, p=.891)$ 과 일반적인 주제의 오리진-폰 비율 $(t(10)=.789, p=.448)$, 여성대학생의 의사소통 관련 오리진-폰 비율 $(t(10)=.884, p=.397)$ 과 일반적인 주제의 오리진-폰 비율 $(t(10)=-.490, p=.635)$ 은 오리진-폰 점수의 균형된 상태인 100 과 통계적으로 유의하게 다르지 않았다.

\section{논의}

남녀대학생을 대상으로 일반적인 주제의 글과 의사소통 관련 글 에서 나타난 인과소를 분석한 결과, 우선 글쓰기 주제와 성에 따라 서 글의 길이는 유의한 차이를 보였으나 오리진과 폰 점수에서는 성과 주제에 따른 차이가 통계적으로 유의하지 않았다. 환언하자 면 남성대학생 보다는 여성대학생의 글쓰기 자료가, 그리고 의사소 통 관련 글쓰기 보다는 일상적인 글쓰기 자료가 유의하게 더 길었
으나, 이러한 길이의 차이에도 불구하고 인과소는 성과 주제에 따 른 차이가 통계적으로 유의하게 나타나지 않았다.

우선 성에 따라 글쓰기의 길이가 달리 나타난 것은 의사소통 표 현방식의 성 차이에 기인한 것으로 생각된다. 이전 연구에 따르면 여성의 구어능력이 비록 남성에 비해 더 좋은 편이기는 하지만 그 차이는 매우 적으며(Hyde \& Linn, 1988), 남성과 여성의 읽기 및 쓰 기능력의 차이는 고등학교 졸업시기까지 이어진다고 한다(Gambel \& Hunter, 1999). 더불어 글의 길이는 쓰기발달, 특히 초등학교 저 학년 시기의 쓰기 유창성 발달의 주요한 지표가 될 수 있으나, 초등 학교 이후에는 이보다는 장르 특성의 습득 등이 더 주요한 지표가 될 수 있다(Kamhi \& Catts, 2012; Paul, 2007). 한국어 쓰기연구도 이와 유사한 결과를 보이고 있는데, 중학생의 경우 여학생이 남학 생 보다 더 발달된 쓰기지식과 능력을 보이지만 이와 같은 차이는 고등학생 연령대에서는 관찰되지 않았다(Shin, 2005; Jeong, 2011). 또한 능력의 차이 이외에도 표현방식의 성 차이 또한 이전 연구는 보고하는데, 예를 들어 여성은 남성과 비교, 대명사 사용 등과 같은 쓰기 형태에서 차이를 나타내며(Argamon, Koppel, Fine, \& Shimoni, 2003), Lakoff (1975)는 여성이 사용하는 언어표현의 특징으 로 애매한 어법의 사용, 과잉 공손형, 부가 의문문의 사용 등을 들 고 있다. 더불어 지배적이고 독립적인 남성의 특성과 협력적이고 복 종적인 여성의 특성이 대화에서도 관찰될 수 있으며(Tannen, 1990), 이는 한국여성의 경우 남성보다 들어주기를 더 좋아하며, 사적인 대화를 공적인 대화보다 더 선호하는 것으로 나타났다(Kim, 2004). 본 연구의 쓰기주제는 자신의 사적인 경험을 나타내는 최근 의사 소통 경험이나 가장 흥미로운 일이었다. 이러한 점에 비추어볼 때, 
사적인 대화를 더 선호하는 여성의 특성으로 인하여 본 연구에서 는 여성대학생이 남성대학생보다 더 길게 자료를 작성한 것으로 생 각하는 것이 적절할 것이다.

더불어 주제에 따라 쓰기의 길이가 달랐다는 점은 본 연구에서 사용한 연구방식의 타당성을 간접적으로 지지하는 결과일 것이다. 쓰기에서는 장르에 따라서 구문복잡성 등이 달리 나타나는데, 예 를 들어 이야기글(narrative) 보다는 논설문의 구문이 더 복잡해진 다(Paul, 2007). 본 연구의 참여자들은 특수한 주제인 최근 의사소 통 경험 보다는 좀 더 일반적인 주제인 인생에서 가장 흥미로웠던 일이라는 주제에 대해서 더 길게 글쓰기를 하였는데, 이는 연구참 여자들이 두 가지 주제에 대해서 서로 다른 심리적 반응을 보였기 때문일 것이다.

위와 같은 주제에 따른 글쓰기 길이의 차이에도 불구하고 글쓰 기 주제에 따라서 인과소에서 통계적으로 유의한 차이가 나타나지 않은 것은 개인의 의사소통스타일과 의사소통능력에 대한 믿음은 개인의 가치와 성격에 영향을 받을 수 있기 때문일 것이다(Gudyn-

kunst et al., 1996; Richmond, McCroskey, \& McCroskey, 1989). 예 를 들어 Richmond 등(1989)은 개인이 자신의 의사소통 능력에 대 한 믿음은 자존감, 내향성, 사회성 등과 관련이 있음을 보고하였다. 이러한 점에 비추어 볼 때, 일반성인이 큰 문제가 없는 자신의 의사 소통에 대해서 느끼는 인과소 정도는 일반적인 성향과 관련이 있으 며, 본 연구결과와 같이 일반적인 성향과 의사소통 관련 인과소 사 이에서 유의한차이가 나타나지 않은 것으로 보인다.

인과소는 주제뿐 아니라 성에 따라서도 통계적으로 유의한 차이 를 나타내지 않았으나, 이러한 결과를 해석하는 데에는 주의가 필 요할 것이다. 우선 전술하였듯이 본 연구의 남성대학생은 여성대학 생과 비교, 비록 통계적으로 유의한 차이를 나타내지는 못하였으 나 모든 상황에서 오리진과 폰 점수가 더 높은 경향을 나타내었다. 즉 비록 본 연구의 남성대학생이 여성대학생과 비교, 통계적으로 유의하게 짧게 글쓰기를 하였으나, 남성대학생이 여성대학생보다 오리진과 폰 관련 진술을 더 많이 하였다는 점을 의미한다. 하지만 오리진과 폰 점수비율은 여성대학생이 최고점과 최소점을 모두 나 타내었으며, 이는 여성대학생이 남성대학생보다 좀 더 강한 한 가지 성향을 보인다는 점을 시사한다. 더불어 Cohen's d로 측정된 성에 따른 인과소 차이의 효과크기는 0.1-0.98까지 다양하게 나타났다. 가장 작은 차이에서 큰 차이를 보인 순서로 배열하자면, 일반적인 주제를 대상으로 한 폰(0.1), 의사소통 관련 오리진(0.3), 일반적인 주제를 대상으로 한 오리진(0.68), 그리고 의사소통 관련 폰(0.98)이 었다. 이러한 결과는 특히 일반적인 주제인 경우 오리진 점수의 남 녀 차이가 중간 정도의 크기이며, 의사소통 관련 폰 점수의 경우 성
에 따른 차이가 매우 큰 것으로 해석된다(Cohen, 1988). 환언하자 면 비록 성에 따른 인과소의 차이가 통계적으로 유의하지는 않았 으나, 임상적인 관점에서는 일반적인 상황에서는 여성대학생과 비 교, 남성대학생이 더 높은 오리진 성향을, 그리고 의사소통과 관련 해서는 여성대학생에 비해 남성대학생이 더 높은 폰 성향을 보이는 것으로 해석될 수 있다. 이는 전술하였듯이, 오리진과 폰은 각각 내 재적 통제소, 외재적 통제소와 유사한 특성을 보이기에, 본 연구의 결과는 남성대학생이 여성대학생에 비하여 일반적 혹은 전체적인 성향으로는 더 높은 내재적 통제소를 보였다는 이전의 결과를 지 지한다. 또한 의사소통과 관련해서는 남성대학생이 더 높은 외재적 통제소와 유사한 특성을 보인 것으로 생각할 수 있는데, 이는 우선 여성대학생이 남성대학생에 비하여 더 높은 의사소통능력을 갖고 있다고 스스로 믿고 있으며, 남성대학생이 의사소통 시 주위 환경 의 영향에 더 민감하게 반응하기 때문인 것으로 추측할 수 있다. 이 와 관련하여 De Nil과 Kroll (1995)은 외재적 성향이 꼭 부정적인 특성을 의미하는 것은 아니라고 하였는데, 이는 외재적 성향이 자 신의 능력을 객관적으로 살피고 주위의 영향을 적절히 판단하는 데 도움을 줄 수 있기 때문이다. 더불어 본 연구에서는 일반적인 상 황에서의 인과소 보다는 의사소통 관련 인과소에서 성 차이가 더 두드러진 결과를 보였는데, 이러한 결과는 일반적인 신념 체계에서 는 남녀 성 차이가 그리 크지 않지만 특정 상황 혹은 환경에 대한 반응의 성 차이는 있을 수 있다는 점을 시사한다.

또한 본 연구결과는 오리진과 폰 점수 비율이 서로 다른 성향을 나타내는 집단의 비교나 상이한 연구방법을 이용한 연구를 서로 비교할 수 있는 간접적인 방법을 제공할 수 있다는 점을 시사한다. 본 연구는 이전 연구와는 다른 연구방법을 사용하였기에 오리진과 폰 점수 자체를 직접적으로 이전 연구와 비교하기에는 무리가 따를 것이다. 하지만 본 연구에서 보고된 오리진과 폰 비율을 기존의 연 구와 비교하면 다음과 같다. 비록 이전 연구들이 오리진과 폰 점수 비율을 보고하지는 않았으나 발표된 자료를 이용하여 이를 산출한 결과, 말더듬성인의 의사소통 관련 오리진-폰 점수 비율은 치료를 받기 전에는 61을, 치료를 받은 후에는 153.8이었다(Lee et al., 2011). Westbrook과 Viney (1980)가 보고한 아홉 집단의 일반적인 성향으 로의 오리진과 폰 비율은 61-106이었는데, 가장 큰 비율, 즉 높은 오 리진 성향을 보인 집단은 성공적인 대학생(106)이었으며, 가장 적은 비율, 즉 높은 폰 성향을 보인 집단은 사지마비집단(61)이었으며, 그 외 다른 집단 역시 100 을 넘기지는 못하였다. 이러한 결과는 일반적 인 성향보다는 의사소통이라는 좀 더 특수한 상황 관련 인과소가 좀 더 다양하게 나타날 수 있음을 시사한다. 예를 들어 본 연구의 남녀대학생이 보인 의사소통 관련 오리진-폰 비율은 모두 100 이상 
이었으나 말더듬성인이 치료 후에 보인 비율보다는 적은 편이었는 데, 이는 말더듬성인의 치료 후 고양된 오리진 인식의 영향일 것이 다(Lee et al., 2011). 하지만 남녀대학생의 일반적인 성향으로의 오 리진-폰 비율은 특히 남성대학생의 경우, 해외자료보다 상당히 높 은 오리진 성향을 나타내었는데, 이는 남성성을 바라보는 문화적인 차이일 것으로 추측된다.

또한 본 연구에 참여한 남녀대학생은 균형된 상태의 오리진-폰 점수 비율을 보였는데, 이와 같은 균형된 인과소 비율은 의사소통 장애를 지닌 사람의 장기적인 치료 목표가 될 수 있을 것이다. 본 연 구의 참여자가 보인 일반적인 성향과 의사소통 관련 오리진-폰 비 율은 오리진 점수와 폰 점수가 균형을 이룬 상태인 100과 통계적으 로 유의하게 다르지 않았으며, 주제와 성에 따른 차이도 통계적으 로 유의하지 않았다. 본 연구의 참여자인 의사소통에 문제가 없는 일반 남녀대학생은 의사소통에 대해서 자신의 능력을 인정하고 대 화를 주도해 나가는 정도로 외부환경의 영향 역시 인지한다는 점 에서 균형된 오리진과 폰 점수 비율을 보인 것이며, 이러한 능력의 균형적인 발전을 통하여 성공적인 의사소통을 해온 것으로 추측된 다. 예를 들어 대화 상대자의 이해능력 정도를 판단할 줄 아는 능력 을 포함하는 메타언어능력의 발달이 학령기 언어발달의 주요한 지 표가 될 수 있는데(Paul, 2007), 본 연구에서 나타난 일반남녀대학 생의 의사소통과 관련된 균형적인 인과소 비율은 일반성인은 자신 의 능력뿐 아니라 외부환경의 의사소통에 대한 영향 역시 적절히 인지할 수 있음을 나타낸 것으로 판단된다. 특히 말더듬성인은 치 료 후 재발이 문제가 될 수 있는데, 이와 같은 재발을 방지하기 위해 서는 자신이 말더듬성인이 아니라 말을 더듬지 않는, 유창한 성인 으로 인식하는 인지적인 변화가 필요하다(DiLollo, Neimeyer, \& Manning, 2002). 이처럼 재발을 방지하기 위한 인지적인 변화의 지 표로 인과소가 사용될 수 있음을 Lee 등(2011)은 지적하였는데, 본 연구결과는 특히 단순히 과도한 오리진의 증가가 아닌, 일반성인이 의사소통에 대해서 갖게 되는 오리진과 폰의 균형된 형태, 즉 자신 의 문제와 환경의 영향에 대해서 적절한 인식을 갖는 것이 말더듬 의 재발을 방지하기 위한 적절한 인지적인 변화형태임을 시사한다.

본 연구에는 다음과 같은 제한점이 있다. 우선 참가자의 수와 특 성이 제한적이었다. 본 연구에는 상대적으로 적은 수의 대구 - 경북 지역의 참여자만 있었으며, 통계적으로 유의한 차이와 유의하지 않 은 차이를 모두 보고하였다. 특히 통계적으로 유의하지는 않았지만 인과소 차이의 효과크기는 상대적으로 큰 편이었다. 전술하였듯이 본 연구의 주제인 인과소에 영향을 끼치는 요소에 대한 실증적인 연구는 부족한 편이나 인과소와 유사한 개념인 통제소의 경우 인 종과 같은 사회문화적 요소, 사회경제적 위치와 같은 사회경제적
요소가 영향을 주는 것으로 보고되었으며, 개인적인 경험과 다른 심리적인 특성 역시 인과소와 관련이 있을 것으로 추측된다. 그러 므로 좀 더 통제된 상황에서의 다수의 참여자를 대상으로 하는 연 구는 성과상황에 따른 인과소의 차이를 좀 더 분명하게 나타낼 수 있을 것으로 예상된다. 예를 들어 대상자의 사회경제적위치(SES), 전공, 학년, 기타 사회경험 등과 같은 요소들이 인과소에 영향을 끼 칠 수 있으므로 이에 대한 통제를 한 연구가 필요할 것이다.

이와 관련하여 본 연구결과의 일반화에도 제한이 있을 수 있다. 전술한 바와 같이 인과소와 같은 심리적 특성은 문화적 차이가 있 을 수 있기에, 다른 연령대, 지역, 경험을 지닌 일반인에게 본 연구의 결과를 일반화시키는 데에는 제약이 있을 수 있을 것이다. 더불어 본 연구에서는 최근 경험에 대한 쓰기자료를 이용하여 인과소를 측정하였는데, 이는 제약 없이 산출된 대상자의 자유로운 발화의 객관적인 분석은 대상자의 심리적인 특성을 민감하고도 충실하게 나타낼 수 있다는 내용분석의 전제에 근거한 것이었다(Gottschalk \& Gleser, 1969). 하지만 쓰기시간조절 혹은 말하기 등의 방식을 이 용하여 대상자가 자신의 경험을 좀 더 다양하고 폭 넓게 진술하여 좀 더 일반적인 특성을 측정하는 추후 연구가 필요할 수 있을 것이 다. 더불어 앞서 제시된 요소를 통제한 상태에서의 일반인과 장애 를 지닌 사람과의 비교를 하여야 할 것이다.

본 연구의 학문적, 임상적 제언은 다음과 같다. 우선 내용분석을 한국어에 적용하기 위한 세련화가 필요하다. 전술하였듯이 본 연구 에서는 변환점수를 산출하는데 사용하는 쓰기자료의 단위로 어절 을 사용하였으나, 해외 영어자료는 단어를 이용하여 변환점수를 산출하였다. 영어의 단어와 한국어 어절 모두 띄어쓰기의 단위가 되며, 계산하는데 수월하기에 쓰기자료의 길이를 측정하는데 유용 하게 사용될 수 있다. 하지만 자료의 길이를 측정하고 변환점수를 산출하는데 해외 자료와 마찬가지로 단어를 이용할지, 아니면 본 연구에서 사용된 어절, 혹은 분석의 대상인 절을 이용하는 것 중 어떤 것이 적절할 지에 대한 추후 연구가 필요하다. 또한 다양한 집 단을 대상으로 하는 표준화점수의 구축이 필요할 것이다. 전술하 였듯이 변화를 촉진하고 유지하는데 인과소의 변화가 중요한 역할 을 할 수 있으므로 여러 장애영역에서 인과소의 측정 및 변화에 대 한 임상적인 연구가 필요할 것이다. 이와 같은 연구를 위해서는 다 양한 연령과 직업 군 등으로 이루어진 일반인을 대상으로 하는 인 과소 측정 연구 역시 필요할 것이다.

\section{결론}

본 연구는 내용분석을 이용하여 일반대학생의 인과소를 분석한 
결과, 의사소통관련 인과소와 일반적 특성으로의 인과소 사이에 는 유의한 차이가 나타나지 않았으며, 두 가지 인과소 모두 오리진 과 폰의 균형된 패턴을 보였다. 또한 성에 따른 차이 역시 통계적으 로는 유의한 결과를 나타내지 않았다. 이러한 결과는 일반성인의 경우, 의사소통을 자연스럽게 받아들이는 경향을 보이고, 의사소 통에 대한 환경의 영향과 자신의 능력을 적절히 판단하고 있음을 나타낸다. 이러한 일반적인 인지적인 과정은 성에 따라 큰 차이가 나타나지 않으나상황에 따라 그 차이가 좀 더 잘 나타날 수 있음을 본 연구결과는 시사한다.

\section{REFERENCES}

Ajzen, I. (2002). Perceived behavior control, self-efficacy, locus of control and the theory of planned behavior. Journal of Applied Social Psychology, 32, 665-683.

Argamon, S., Koppel, M., Fine, J., \& Shimoni, A. R. (2003). Gender, genre, and writing style in formal written texts. Text, 23, 321-346.

Benassi, V. A., Sweeney, P. D., \& Dufour, C. L. (1988). Is there a relation between locus of control orientation and depression? Journal of Abnormal Psychology, 97, 357-367.

Cohen, J. (1988). Statistical power analysis for the behavioral sciences (2nd ed.). Hillsdale, NJ: Lawrence Erlbaum Associates.

Craig, A., Franklin, J., \& Andrews, G. (1984). A scale to measure locus of control of behavior. British Journal of Medical Psychology, 57, 173-180.

DeCharms, R. (1968). Personal causation: the internal affective determinants of behavior. New York, NY: Academic Press.

De Nil, L. F., \& Brutten, G. J. (1991). Speech-associated attitudes of stuttering and nonstuttering children. Journal of Speech and Hearing Research, 34, 60-66.

De Nil, L. F., \& Kroll, R. M. (1995). The relationship between locus of control and long-term stuttering treatment outcome in adult stutterers. Journal of Fluency Disorders, 20, 345-364.

DiLollo, A. (2001). The meaningfulness of speaker roles for fluent speakers and persons who stutter (Doctoral dissertation), The University of Memphis, Memphis, TN.

DiLollo, A., Neimeyer, R. A., \& Manning, W. H. (2002). A personal construct psychology view of relapse: indications for a narrative therapy component to stuttering treatment. Journal of Fluency Disorders, 27, 19-42.

Eagly, A. H., \& Carli, L. L. (1981). Sex of researchers and sex-typed communications as determinants of sex difference in influenceability: a meta-anal- ysis of social influence studies. Psychological Bulletin, 90, 1-20.

Eagly, A. H., \& Steffen, V. J. (1986). Gender and aggressive behavior: a metaanalytic review of the social psychological literature. Psychological Bulletin, 100, 309-330.

Finn, P. (1996). Establishing the validity of recovery from stuttering without formal treatment. Journal of Speech and Hearing Research, 39, 1171-1181.

Gambel, T. J., \& Hunter, D. M. (1999). Rethinking gender differences in literacy. Canadian Journal of Education, 24, 1-16.

Garstecki, D. C., \& Erler S. F. (1998). Hearing loss, control, and demographic factors influencing hearing aid use among older adults. Journal of Speech, Language, and Hearing Research, 41, 527-537.

Gergen, K. J. (1985). The social constructionist movement in modern psychology. American Psychologist, 40, 266-275.

Gottschalk, L. A., \& Gleser, G. C. (1969). The measurement of psychological states through the content analysis of verbal behavior. Berkeley, CA: University of California Press.

Gudynkunst, W. B., Matsumoto, Y., Ting-Toomey, S., Nishida, T., Kim, K., \& Heyman, S. (1996). The influence of cultural individualism-collectivism, self construals, and individual values on communication styles across cultures. Human Communication Research, 22, 510-543.

Gurin, P., Gurin, G., \& Morrison, B. M. (1978). Personal and ideological aspects of internal and external control. Social Psychology, 41, 275-296.

Hyde, J. S., \& Linn, M. C. (1988). Gender differences in verbal ability: a metaanalysis. Psychological Bulletin, 104, 53-69.

Jeong, M. (2011). A study on the correlation of writing knowledge and performance. Journal of Korean Arts Education Research, 18, 213-248.

Kamhi, H. W., \& Catts, A. G. (2012). Language and reading disabilities (3rd ed.). Upper Saddle River, NJ: The Allyn and Bacon.

Kim, S. (2004). Gender differences in conversational styles of students. Journal of Korean Home Management Association, 22, 219-232.

Lakoff, R. (1975). Language and woman's place. New York: Harper \& Row.

Lee, K., Manning, W. H., \& Herder, C. (2011). Documenting changes in adult speakers' locus of causality during stuttering treatment using Origin and Pawn scaling. Journal of Fluency Disorders, 36, 231-245.

Lee, K., \& Shin, M. (2010). The Origin and Pawn analysis of writing samples of Korean adults who stutter. Korean Journal of Communication Disorders, $15,433-443$.

Lefcourt, H. M. (1992). Durability and impact of the locus of control construct. Psychological Bulletin, 112, 411-414.

Maccoby, E. E., \& Jacklin, C. N. (1974). The psychology of sex differences. Stan- 
ford, CA: Stanford University Press.

Manning, W. H. (2010). Clinical decision making in fluency disorders (3rd ed.). Clifton Park, NY: Delmar Cengage Learning.

Marks, L. I. (1998). Deconstruction locus of control: implications for practitioner. Journal of Counseling and Development, 76, 251-260.

Paul, R. (2007). Language disorders from infancy through adolescence: assessment and intervention (3rd ed.). St. Louis, MO: Mosby.

Plimpton, F. H. (1970). The effects of motivation training upon the origin syndrome (Doctoral dissertation), Washington University, St. Louis, MO.

Richmond, V. P., McCroskey, J. C., \& McCrosky, L. L. (1989). An investigation of self-perceived competence and personality orientations. Communication Research Reports, 6, 28-36.

Rotter, J. B. (1966). Generalized expectancies for internal versus external control reinforcement. Psychological Monograps: General and Applied, 80, 1-28.

Schulz, R., Heckhausen, J., \& Locher, J. L. (1991). Adult development, control, and adaptive functioning. Journal of Social Issues, 47, 177-196.

Shin, H. (2005). Influences of cognitive/motivational variables and gender on writing performance of high school students. Korean Journal of School Psychology, 2, 149-175.

Silverman, E. M. (1980). Communication attitudes of women who stutter. Journal of Speech and Hearing Disorders, 45, 533-539.

Strickland, B. R. (1989). Internal-external control expectancies: from contingency to creativity. American Psychologist, 44, 1-12.

Tannen, D. (1990). You just don't understand: women and men in conversation. New York, NY: William Morrow \& Company.

Viney, L. L. (1983). The assessment of psychological states through content analysis of verbal communications. Psychological Bulletin, 94, 542-563.

Westbrook, M. T., \& Viney, L. L. (1980). Scales measuring people’s perception of themselves as Origins and Pawns. Journal of Personality Assessment, 44, 167-174

Yaruss, J. S., \& Quesal, R. W. (2004). Stuttering and the International Classification of Functioning, Disability, and Health (ICF): an update. Journal of Fluency Disorders, 37, 35-52. 


\section{국문초록}

\section{일반 대학생의 글쓰기 분석을 통한 성별과 주제에 따른 인과소 차이 \\ 이경재}

대구가톨릭대학교 언어청각치료학과

배경 및 목적: 행동의 변화를 촉진하고 유지하는데 중요한 요소 중 하나는 인과소(locus of causality)이다. 인과소란 행동의 원인이 자 신 내부에 있는지 혹은 외부에 있는지에 대한 행위자의 믿음이며, 이를 각각 오리진(Origin)과 폰(Pawn)이라고 한다. 이전 해외 연구에 서는 일반적인 주제 혹은 의사소통관련 주제의 글쓰기를 내용분석하여 인과소를 측정하였으며, 국내연구는 주로 말더듬남자성인을 대상으로 의사소통 관련 인과소를 측정하였다. 본 연구의 목적은 일반 대학생을 대상으로 인과소와 글의 길이가 성별에 따라, 그리고 글쓰기 주제에 따라 다르게 나타나는지 알아보는 것이다. 본 연구는 의사소통에 대한 일반 대학생의 인식을 분석하며, 이후 의사소통 장애를 지닌 사람들과의 비교연구에 기초자료를 제공한다는 의의가 있다. 방법: 남녀대학생 총 22 명이 작성한 두 가지 주제의 글쓰기 자료를 내용분석하여 의사소통 관련 인과소와 일반적인 성향으로의 인과소를 측정하여, 이러한 인과소가 성별에 따라, 그리고 글쓰기 주제에 따라 달리 나타나는지 비교하였다. 더불어 인과소 분석의 자료가 되는 글쓰기의 길이가 성별과 주제에 따라차이가 나타나는지 도 살펴보았다. 결과: 글쓰기의 길이는 성별에 따라, 그리고 주제에 따라 통계적으로 유의한 차이를 보였다. 하지만 인과소는 성별과 주 제에 따른 차이가 통계적으로 유의하지는 않았지만 중간 이상의 효과크기를 나타내었다. 논의 및 결론: 본 연구의 결과는 일반 대학생 의 의사소통 관련 인과소는 일반적인 성향에 바탕을 두고 있다는 점을 시사한다. 또한 의사소통 관련 인지적 반응의 성 차이는 미묘할 수 있으므로 추후 좀 더 통제된 상황에서의, 다수의 참여자를 대상으로 하는 연구가 필요할 것이다.

핵심어: 인과소, 오리진, 폰, 성 차이, 의사소통 성향

이 논문은 2012년도 대구가톨릭대학교 교내연구비 지원에 의한 것임.

\section{참고문헌}

김성희(2004). 대화방식에서의 성차이. 한국가정관리학회지, 22, 219-232.

신현숙(2005). 인지적 및 동기적 변인들과 성별이 고등학생의 텍스트 유형별 쓰기 수행에 미치는 영향. 한국심리학회지, 2, 149-175.

이경재, 신문자(2010). 한국 말더듬 성인 쓰기 내용의 오리진과 폰 분석. 언어청각장애연구, 15, 433-443.

정미경(2011). 쓰기 지식과 쓰기 수행의 상관성 연구. 국어교과교육연구, 18, 213-248. 